\title{
SEWPS
}

SPRU Electronic Working Paper Series

\author{
Paper No. 150
}

\section{Expectations, Network Effects and Timing of Technology Adoption: Some Empirical Evidence from a Sample of SMEs in Italy}

Nicoletta Corrocher* and Roberto Fontana**

$\left({ }^{*}\right.$ CESPRI, Bocconi University, ${ }^{* *}$ University of Pavia and CESPRI)

\section{April 2006}

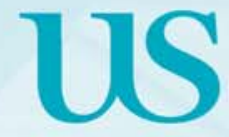

University of Sussex

SPRU - Science \& Technology Policy Research
The Freeman Centre, University of Sussex, Falmer, Brighton BN1 9QE, UK Tel: +44(0) 1273678066 E-mail: sprupubl@sussex.ac.uk http://www.sussex.ac.uk/spru/ 


\title{
Expectations, Network Effects and Timing of Technology Adoption: Some Empirical Evidence from a Sample of SMEs in Italy
}

\author{
Nicoletta Corrocher* and Roberto Fontana**
}

We provide evidence on the influence of expectations and network effects on the timing of technological adoption. By considering a sample of SMEs operating in Italy we focus on the determinants of their decision to adopt Fast Ethernet, a communication standard for Local Area Networks (LANs). We find that both expectations and network effects significantly affect the timing of adoption. In particular, price expectations generally tend to delay adoption and (indirect) network effects in the form of backward compatibility as well as informational spillovers tend to foster adoption. Firm size also matters.

Keywords: Diffusion, Network Effects, Expectations, LAN equipment

JEL: O33, L63

Earlier versions of this paper were presented at the DRUID Summer Conference 2005 Copenhagen and the workshop on Demand, Innovation and Industrial Dynamics 2005 Milan. The comments and suggestions of participants at these meetings are much appreciated. Financial support from the Italian Ministry of Research (MIUR - n²003137229) is acknowledged.

* CESPRI, Bocconi University, Via Sarfatti 25, 20139, Milano; Phone: (+) 3902 58363396; Fax: (+) 390258363399 ;

Email: nicoletta.corrocher@unibocconi.it

** University of Pavia, Department of Economics, Via San Felice, 5 - 27100 Pavia and CESPRI, Bocconi University, Via Sarfatti 25, 20139, Milano; Phone: (+) 3902 58363037; Fax: (+) 3902 58363399;

Email: $\underline{\text { roberto.fontana@unibocconi.it }}$ 


\section{Introduction}

A huge body of both theoretical and empirical literature deals with the issue of innovation diffusion. Theoretical models offer predictions on the characteristics of early and late adopters who are expected to adopt. Empirical studies test these predictions. A common set of factors that are typically found to affect adoption at a point in time are firm size and R\&D intensity. Most of the empirical studies tend to focus on the determinants of diffusion by actually providing evidence on the probability to adopt. A few empirical studies instead analyse the factors affecting the timing of adoption.

Among the most important factors affecting timing of adoption there are price and technological expectations as well as network effects. Expected improvements in the innovation and/or the likelihood that it will experience improvements in the near future contribute to postpone adoption (Balcer and Lippman, 1984). Beside expectations, timing of adoption is also likely to be influenced by network effects (Church and Gandal, 2004). In the presence of network effects, the utility from adoption increases in the number of other adopters that purchase the innovation. Interdependence among adopters is a powerful source of positive feedbacks for adopters who must decide when to adopt, taking into account both the current network size and its perspectives for future growth. There is little empirical evidence on the impact of expectations on adoption, the only work being that of Weiss (1996), which provides empirical support to the hypothesis that technological expectations delay adoption. Many empirical studies look instead at the impact of the presence of network effects on timing of adoption. These studies generally rely on indirect measures of network effects such as network size (Dranove and Gandal, 2003; Gandal et al., 2000), or employ duration models to estimate the probability of transition from a non adopter to an adopter status (Saloner and Shepard, 1995).

This paper provides empirical evidence on the impact of expectations and network effects on timing of adoption. In particular, it considers the case of the adoption of Fast Ethernet, a high speed standard for Local Area Networks (LANs). The data used in this paper come from a survey of 128 small and medium size enterprises operating in Italy that have a LAN in place. The survey was carried out in December 2003 and was 
intended to investigate the impact of expectations and network effects on the speed of LAN upgrade from the standard in place (Ethernet) to a faster though compatible standard (Fast Ethernet). The cross section provides information on when Fast Ethernet was adopted, the characteristics of the respondent firms such as size, type of activity, as well as information on the determinants of their adoption choices in general and with specific regard to the decision to upgrade their network.

The econometric estimation enables us to study the determinants of differences of behaviour across the surveyed firms categorised with respect to when they first adopted Fast Ethernet (i.e. pioneers, early adopters, laggards). In particular, we address the following question: how did expectations and network effects influence the differentials in timing of Fast Ethernet adoption across the firms in our sample? Particular attention is devoted to the identification of the role played by different mechanisms underling network effects. We are able to directly measure the influence of different types of network effects on adoption behaviour and asses the way they impact on timing of adoption while controlling for sample selection bias.

The structure of the paper is as follows. Next section reviews the existing empirical and theoretical contributions on expectations and network externalities as determinants of timing of technology adoption. Section 3 provides the background on the LAN technology and industry to put the case of Fast Ethernet adoption in context. Section 4 describes the sample and the structure of our survey. Section 5 presents the empirical models and the results. Conclusions and limitations of the paper are discussed in Section 6.

\section{Expectations, network effects and timing of adoption: a literature review} What influences the timing of adoption of a new technology? The existing literature on innovation draws different conclusions on the factors affecting adoption, on the basis of the assumptions and the viewpoint taken by each specific model. Equilibrium models for instance, consider the case of heterogeneous potential adopters who are informed on the existence of the technology and evaluate the opportunity of adoption by comparing 
gross benefits and costs from the acquisition. ${ }^{1}$ Individual adoption occurs, if benefits exceed adoption costs. If decisions are taken in sequence, a diffusion path emerges which can be determined as the outcome of a series of individual decisions. Indeed, the theoretical literature typically identifies the factors that characterise early and late decisions. Changes in the costs and/or benefits from adoption are necessary to ensure that adoptions occur in sequence.

The individual timing of adoption depends on how gross benefits and adoption costs are distributed across potential adopters. For instance, if all adopters have the same adoption costs at a point in time, it is reasonable to expect firms that gain the highest benefits to be the early adopters and those who gain less to be laggards. If, instead, benefits are the same and invariant across the population of firms we expect firms with the lowest costs to be the pioneers. Different variants of this basic model exist in the literature. Contributions vary according to the attention placed on specific factors affecting adoption costs and benefits and their rate of change.

Within this theoretical set up, empirical studies focus on the probability of a firm having adopted an innovation by a given time. For instance, low acquisition costs and decreases in such costs tend to increase adoption probability (Ireland and Stoneman, 1983; David and Olsen, 1986). Firm size increases the probability too, either by increasing the extent of returns from innovation (David, 1969), or by improving returns to scale (Davies, 1979). R\&D expenditures as an indicator of absorptive capacity for the new technology have also been considered an important determinant of adoption. Firms that perform more $R \& D$ are highly receptive to a new technology and have a higher probability to adopt than those that carry out less R\&D (Cohen and Levinthal, 1989).

Both firm size and R\&D expenditures are easily measurable and stable over time. Being relatively time invariant factors, they can be used to characterise early and late adopters with respect to their probability to adopt. Other factors are less time invariant and tend to affect the timing of adoption rather than the probability to adopt at a point in time. For instance, consider price and technological expectations. The paramount role of 
expectations in influencing timing of adoption has been explicitly recognised since the seminal contribution of Rosenberg (1976). Potential adopters may delay adoption if they expect the price of innovation to decline in the near future. Moreover, waiting for 'bugs to be fixed', prototypes to be refined and more in general technical improvements to occur can be another important source of delay. These intuitions have been successfully confirmed and incorporated into formal models of adoption (Balcer and Lippman, 1984). Empirical evidence on the effects of expectations on timing of adoption is rather scarce. Weiss (1996) empirically tests the predictions of the model of Balcer and Lippman on a sample of firms considering the adoption of surface mount technology, a process innovation for assembling circuit boards. He finds that technological expectations in the form of greater expected improvements tend to delay adoption and contribute to stall the diffusion of this specific process innovation.

The time, rather than the probability, of adoption may also depend on the technology to be used alongside another technology and/or the adopter becoming part of a network of users. Two types of networks are generally identified in the literature: direct and indirect networks. Direct networks arise when adopters become part of a network by purchasing a product that provides a (direct) connection between the adopter and other users who bought the same product. Being able to interact directly with other users is the main source of utility adopters can gain from adopting. Typical examples of direct networks are the telephone exchange and the fax. In the case of indirect networks, adopters gain utility from the joint consumption of two components that interact to form a system. In this case, the product (hardware component) has no direct value for the adopter unless it is used in combination with another product (software component); here vertical compatibility (between the system components) matters. Examples of indirect network can be found in the field of computing (operating systems and application software) and consumer electronics (video cassette systems, compact disks).

Both network types are characterised by the presence of a network effect. A network effect exists "if the value [of adopting a system component] increases in the number of other adopters that (ultimately) join the network by purchasing compatible products" (Church 
and Gandal, 2004; p.4). The source of benefits from the network effect is the same in both types of network and positively depends on the size of the network when adoption occurs. The larger the network, the greater are the benefits from adoption. The mechanisms of transmission of the benefits instead vary according to the type of network. Indeed network size can be a measure of different mechanisms of transmission of the network effect.

In the case of direct network effect, network size approximates the adopter's desire for horizontal compatibility. Having a large network of compatible mobile phone users for instance makes new users more likely to join. When the network effect is indirect, network size can be a proxy for the availability of complementary components of the technical system. In this case network effects are physical in the sense that they require compatibility between the hardware and the software components of the system to operate. The physical network effect is particularly strong when adopters' desire for vertical compatibility and/or variety is high. To the extent that the hardware component is compatible with a wide range of software components, a larger installed base of hardware is an indication of higher benefits for adopters who have a strong preference for variety. System components may undergo technical change. However, as long as backward compatibility is maintained, the network effect ensures that utility from the consumption increases. As we will argue in the next section, this is what happened when Fast Ethernet was introduced in the LAN industry.

Besides being a proxy for desire of horizontal and/or vertical compatibility, network size is also an indicator of the past behaviour of existing users and manufacturers. At a specific point in time, network size conveys to potential adopters information about the characteristics of the technology and the payoff from its adoption, which help firms to make inference on the opportunity to adopt it. In this case network effects are virtual and can be understood as a particular mechanism for conveying learning spillovers. Physical and virtual effects may be combined, as in the model by Choi (1997). In this model, uncertainty exists on the payoffs from adoption and firms make irreversible commitment to one technology by choosing in sequence between two alternatives. 
Within this context, Choi shows that the combination of virtual and physical effects may have ambiguous effects on the timing of adoption of a new technology. On the one hand, informational spillovers from previous adopters encourage further adoption by those who prefer to imitate to avoid the risk of choosing an alternative with a lower payoff. On the other hand spillovers may be a source of inertia. If early adopters are aware of being a source of spillovers, they may delay adoption to avoid the risk of being stranded if, by choosing the other alternative, followers end up enjoying a higher payoff than the known one.

Empirical studies of network effects and diffusion generally fall within two main categories. In the first category there are aggregate (industry) level studies. These studies typically confirm that the presence of network effects foster technology diffusion. They usually rely on network size as an indicator of the existence of network effects. As a consequence, they are generally incapable of singling out the effect on different mechanisms underlying the two types of network effects. Neither do they explicitly address the issue of the determinants of the timing of adoption at the individual firm level.

More interesting for the scope of this paper is the second category: micro (firm) level studies. These contributions employ a variety of econometric approaches to investigate network effects as determinants either of the speed of diffusion, or of the choice among alternative technologies at the individual firm level. Saloner and Shepard (1995) employ duration models to study the diffusion of ATM on a sample of banks in US. They find that banks with many branches, a proxy for the (indirect) network effect, generally adopt ATM machines earlier than banks with fewer branches. Gowrisankaran and Stavins (2002) study the role of network effects in influencing the adoption of automated clearing houses payment systems by a sample of US banks. They find that adoption is positively influenced by the number of banks who have adopted the same technology (direct network effect) as well as, although to a lesser extent, by the number of users of the payment system (indirect virtual effect). Augereau (1999) analyses the adoption of 56K modems by ISPs in US. She finds that, controlling for firms heterogeneity, the 
probability to adopt a certain type of modem increases in the market share of the modem type, therefore providing support for the presence of (indirect) network effects. Finally, Klenow and Goolsbee (1999) consider the diffusion of personal computers across US households. They find a positive relationship between the probability to adopt and the (mean) number of adopters in the same metropolitan area. When trying to assess the contribution of different sources of network effects on this result, they find that these positive effects are more likely to be explained by learning spillovers (i.e. virtual effects) rather than by the use of specific software or by other local effects such as local prices and/or peer pressure. A summary of selected contributions for both categories of studies is reported in Table I below. ${ }^{2}$

\{Insert Table I approximately here\}

This paper takes a micro level approach to study the impact of expectations and network effects on adoption. It considers a cross section of SMEs and identifies several proxies of network effects in order to be able to disentangle the impact of direct and indirect network effects. In the next section we provide a description of the LAN industry and technology and we identify why network effects and expectations are important determinants of the decision to adopt.

\section{Background on the LAN industry and technology}

Local Area Networks (LANs) are technical systems that form the infrastructure connecting PCs, workstations and peripherals across a single or several company sites within an area of relative small dimensions. Being technical systems, LANs are made up of different hardware pieces (i.e. adapter cards, hubs, switches and routers) each of them carrying out a specific function for the purpose of exchanging data. The rules and the speed at which data are exchanged are defined by communication standards (i.e. Ethernet, Token Ring, and Fast Ethernet). LANs started diffusing in firm environments from mid-1970s and since then several standards have characterised the evolution of LAN technology during different phases in the diffusion of LANs (Christensen et al., 1995). During the 1980s Ethernet became the dominant standard (von Burg, 2001). As a 
high speed upgrade to Ethernet, Fast Ethernet was officially standardised in 1993 and became the dominant high speed LAN standard between 1995 and 1998. Figure I below plots the diffusion curve for the standard in the North America market.

\{Insert Figure I approximately here\}

Data report Fast Ethernet shipments for two main categories of LAN equipment (hubs and switches). Fast Ethernet was first implemented in hub equipment but its diffusion received a significant boost with the arrival of switches which currently continue to support the growth, while hubs have become obsolete. This paper analyses the determinants of Fast Ethernet diffusion. In particular we focus on three factors: (indirect) network effects, expectations and switching costs.

Indirect (physical) network effects are important because, to become viable, Fast Ethernet requires to be embedded in components of the 'enabling LAN infrastructure', such as hubs and switches. Being 'physically' compatible with Ethernet makes Fast Ethernet appealing for buyers and attracts high support from manufacturers of both hubs and switches. Wide component availability in turn triggers fast price decline and contributes to make the standard popular. Alongside physical indirect effect, learning effects can also influence adoption. Although Fast Ethernet is a non proprietary standard, its implementation (i.e. setting-up and connection) and management (i.e. configuration and troubleshooting) is carried out by specific software packages. These packages are 'vendor specific' and sometimes incompatible across manufacturers. Learning how to use the software to perform these activities takes time and requires training. Forman and Chen (2004) provide evidence on the impact of learning on LAN equipment adoption. In particular they find that, after learning how to use software from a specific manufacturer, firms become more likely to continue purchasing equipment from the same manufacturer rather than to switch and incur the costs of retraining. Previous use of vendor specific software generates a powerful network effect that can affect adoption. Rather than deriving from physical compatibility, this effect 
depends on previous learning. It is, so to speak, 'virtual' in the sense defined in Section 2 above.

Both price and technological expectations also affect the decision to adopt Fast Ethernet. The arrival of switches has been accompanied by a dramatic fall in equipment prices. Expectations of further price decline may induce firms that have not yet adopted to further defer adoption. Moreover, today Fast Ethernet is a mature and established standard. Its characteristics are known and the technology fully developed. The existence of another alternative (Gigabit Ethernet) in competition with Fast Ethernet can affect the decision to adopt. Gigabit Ethernet is the third generation upgrade to Ethernet. It is backward compatible with both Ethernet and Fast Ethernet and runs at $1000 \mathrm{Mbps}$ a hundredfold increase in speed with respect to Ethernet (Cheng et al. 2005). Gigabit Ethernet is now fully available in the market, but its commercialisation had just started when our survey was conducted. For those firms that had not yet upgraded their LANs, Gigabit Ethernet could represent an alternative to Fast Ethernet. Expectations of its availability could have influenced the timing of upgrade.

Finally switching costs matter because buyers of LAN standards typically need to make physical changes to their LAN architecture. Adopting a standard may require firms to change existing facilities such as existing wiring and cabling (i.e. from copper wire to fibre), move computers, and reconfiguring existing portions of the network. High switching costs are typically associated to slower adoption.

The variables intended to capture these effects will be presented in Section 5. Next section will present the sample and explain how the survey was carried out.

\section{Sample description and descriptive evidence}

The analysis in this paper focuses on a sample of SMEs in Italy. In particular, it relies on a survey of 128 SMEs that have a LAN in place. These firms operate in the computing service industry (NACE 72). The sample was chosen from the AIDA Dataset that contains balance sheet information on firms operating in Italy. We selected firms in the 
computing service industry, since we believe that high-tech firms should be more inclined to use new technologies. In December 2003, telephone interviews were carried out with the purpose of understanding what were the standards and the type of equipment in place, as well as of identifying the factors affecting the decision to adopt new ones.

For the survey methodology we followed the 'key informant' methodology described in Weiss (1996) aimed at interviewing those people who have a key role in all decision making related to LAN equipment. In particular, interviews were specifically targeted to the personnel in charge of the firm IT budget such as Chief Information Officers or, being the sample made of SMEs, network and/or telecommunications managers. We collected 98 completed questionnaires, which gave us a fairly high response rate $(77 \%)$.

The survey is made of 25 questions and structured in four sections. Section A aims at collecting general information about firms in terms of sector of activity, location, size and revenues. Section B focuses on the technological endowment of firms - in terms of network type (Internetwork, LAN, WAN), number of nodes, type of equipment (i.e. hubs and switches) as well as applications (i.e. client server, email, intranet etc.) in place - and on the costs of acquiring and upgrading the network in terms of human resources and physical investments. Section $C$ analyses objectives, determinants and obstacles to technology adoption, as well as the expectations of firms in terms of price and technological improvements. Section D examines the characteristics of adoption processes, also in relation to the existence of network effects and to the features of the market.

A specific question in the survey asked respondents to report how many months before the survey they first adopted each equipment and standard currently deployed in their network. Four different options were given: a) Less than 12 months before being surveyed, b) Between 12 and 18 months, c) Between 19 and 24 months, d) More than 24 months. Table II reports the number of adopters by standard and timing of first adoption. 
\{Insert Table II approximately here $\}$

As expected, the most common standards are Ethernet and Fast Ethernet adopted by $87 \%$ and $76 \%$ of firms in our sample. Token Ring (24\%) as well as FDDI (12\%) and ATM $(2 \%)$, two high speed standards in competition with Fast Ethernet, are less adopted. Table III reports information on the characteristics of the firms in our sample.

\{Insert Table III approximately here\}

Overall these figures confirm that the majority of firms in our sample are SMEs $(73 \%$ of respondents have less than 500 employees) with small LANs in place ( $82 \%$ of firms have less than 100 nodes connected). Although all firms are located in Italy, the majority of them $(56 \%)$ have an international profile (i.e. they are subsidiaries or units of multinational corporations). From Table III we can also gain preliminary insights on the relationship between firms' characteristics and the pattern of Ethernet and Fast Ethernet adoption. The majority of Ethernet and Fast Ethernet adoption occurred between 18 and 24 months before the survey took place irrespectively from firms' characteristics. As argued in the previous section Ethernet and Fast Ethernet are the most common standards in the LAN environment. Moreover, both standards have been in the market for a while, so that it is not surprising that they were adopted relatively early. ${ }^{3}$

It is interesting to investigate whether there is a relationship between Fast Ethernet adoption and previous use of Ethernet, in particular if having adopted Ethernet affected the timing of Fast Ethernet adoption. In the next section we will explore this possibility.

\section{The empirical analysis of Fast Ethernet adoption}

In this section, we take a micro level perspective to study the factors affecting the speed of Fast Ethernet adoption. As argued in the previous section, $76 \%$ of the firms in our sample adopted Fast Ethernet. A slight majority of them (52\%) adopted Fast Ethernet after Ethernet. Given the high compatibility between Ethernet and Fast Ethernet it could be expected for these firms to prefer Fast Ethernet to the alternatives as high speed 
upgrade for their LANs. However, 47 (48\%) firms in our sample behaved differently. 24 firms adopted Fast Ethernet before adopting Ethernet and 23 had not adopted Fast Ethernet when the survey was carried out, although they had Ethernet in place. In this section we investigate the determinants of this heterogeneity. In particular, we address the following question: how did expectations and network effects influence the differentials in the timing of Fast Ethernet adoption across firms in our sample?

\subsection{Sample selection bias}

In order to answer our research question, we use information on firms that were current users of Fast Ethernet at the time the survey was carried out. To these firms we can assign a specific status according to the speed at which adoption occurred. In particular, we classify firms as Pioneers (those that adopted Fast Ethernet before Ethernet), Early adopters (those that adopted Fast Ethernet within 12 months from the first adoption of Ethernet), Laggards (those that took more than 12 months to upgrade from Ethernet to Fast Ethernet), Non adopters (those that have adopted Ethernet, but not yet upgraded to fast Ethernet). ${ }^{4}$ On the basis of this classification we can create a variable STATUS that takes the value of (0) if the firm is a Pioneer, (1) if the firm is an Early adopter, (2) if the firm is a Laggard, (3) if the firm is a Non adopter. It may be argued that, Non adopters are not current users of Fast Ethernet and should not be included in the same group as Pioneers, Early adopters and Laggards. However, using only information on the subsample of adopters may introduce a sample selection bias. To eliminate the potential source of misspecification, we opt for a two-step estimation model similar to Heckman Procedure for selection bias (Heckman, 1979). In the first step, we use a binary response model to explain the probability of adopting Fast Ethernet as a function of a series of independent variables. In the second step, we focus only on current users to look at the determinants of the timing of adoption, as summarised by the variable STATUS. Here the inverse Mills' ratio from the first stage is used to correct for the selection bias.

\subsection{The variables}

We identify three types of independent variables. Physical network effects 
Physical network effects are associated to the availability of complementary equipment in the market as well as to the degree of compatibility between the currently deployed standard and the alternative to be chosen. As argued above, many firms that adopted Fast Ethernet had previously adopted Ethernet. To understand whether this previous status may have influenced the timing of Fast Ethernet adoption, we asked respondents to measure on a four points scale the importance of backward compatibility when planning a migration to a new standard and/or technology. Responses were used to construct the variable TECHCOMP that varies between 1 ("not at all important") and 4 ("very important"). We expect a high likelihood to adopt early for firms that score high on this variable.

\section{'Virtual' network effects}

As argued in Section 2, virtual network effects are mainly generated by information spillovers about the technology and the payoff from its adoption. Spillovers may arise from the size of the existing network of Fast Ethernet adopters, the rationale being that, by observing past behaviours, firms draw information about the characteristics of Fast Ethernet and the opportunity to upgrade. To capture the effect of spillovers from past adoption, we asked a firm to report how desirable is to be compatible with most of the other firms when buying a new product supporting a specific standard. Four possible options were given ranging from "not at all desirable" to "extremely desirable". The variable BANDWG that varies from 1 ("not at all desirable") to 4 ("extremely desirable") categorises the responses. This type of spillover may speed up or delay adoption.

In Section 3 we also argued that adoption can be influenced by the extent of previous learning accumulated in the use of software to manage the network, particularly when this software is 'vendor specific'. To capture this influence on the speed of upgrade, we asked firms to report how important it is to buy from a vendor with whom the firm has entertained commercial relationships in the past. Again responses were coded on a four point scale (with "not at all important" and "extremely important" as anchor points) and were used to construct the variable VENDCOMP that varies between 1 and 4 . Firms that score high on this variable show a preference for vendor compatibility. This preference 
can either speed up or delay adoption in those cases in which buyers do not want to run the risk of being locked-in to a specific vendor. We do not make hypotheses on the direction of the impact of this effect on timing of adoption.

\section{Expectations}

We distinguish between two types of expectations: price expectations and technological expectations. To capture the influence of price expectations on the decision to adopt, we asked firms to assess on a four points scale (with "not at all influential" and "highly influential" as anchor points) the extent to what 'waiting for the price of the technology to decline' was influential on their decision to migrate to the new technology. We then used the responses to construct the variable PRICEEXP that varies between 1 and 4 . By the same token, the role of technological expectations was assessed by asking firms to rate on the same type of scale to what extent 'waiting for the technology to mature' was influential and by constructing the variable TECHEXP that varies between 1 and 4 . On the basis of the existing theoretical as well as empirical literature we expect, in both cases, that firms with a higher score are more likely to delay adoption.

\section{Additional variables}

In the selection equation, we control for two additional determinants of adoption: firm size and switching costs. Firm size is expected to play an important role in adoption for at least two reasons. First, as stressed in Section 2, larger firms have generally more resources to invest, may enjoy higher returns from adoption and are usually more prone to risk. Second, the larger the firm, the wider the network currently in use and the more likely it is that congestion will be experienced. Demand for high speed standard such as Fast Ethernet is higher in highly congested networks. We should therefore expect larger firms to have a higher probability of adoption. Our measure of size is the firm annual revenues in the latest year preceding the survey. We identified six possible intervals and asked firms to select one of them. Our measure SIZE is a variable that varies between 1 ("annual revenue $\leq 50 \mathrm{~K}$ euros") and 6 ("annual revenue $>10$ milion euros"). 
As argued in Section 3, switching costs may also affect Fast Ethernet adoption. We have identified three cost components of running a LAN: Capital Equipment costs deriving from the purchase of the hardware necessary to implement the standards (i.e. hubs, switches, routers); Facilities costs (i.e. costs for wiring/cabling, equipment and software maintenance); Personnel/Human capital costs (i.e. costs for network design and management support and training). We asked firms to give an estimate of the share of each component over the total. SWCOST is a variable that considers the sum of the share of capital and personnel costs. We expect firms with higher switching cost to have a lower likelihood to adopt.

Descriptive statistics are reported in the Appendix.

\subsection{Results}

98 firms answered the questionnaire (24 Pioneers, 37 Early adopters, 14 Laggards and 23 Non adopters). As mentioned above, before proceeding with the estimation we must account for sample selection bias. Our selection equation can be written as follows:

$$
\begin{aligned}
& Z_{i j}^{*}=\psi^{\prime} W_{i}+u_{i} \\
& Z_{i}=0 \text { if } \quad \text { STATUS }=3 \quad(\text { Non_adopter }) \\
& Z_{i}=1 \text { if } \quad \text { STATUS }=0,1,2 \quad(\text { Current_user })
\end{aligned}
$$

where $Z_{i j}$ is a latent variable taking the value 0 if the firm is a Non adopter and the 1 if the firms is a current user (i.e. either a Pioneer, or an Early adopter, or a Laggard). $W_{i}$ is a vector of determinants of adoption and $u_{i}$ is a residual which we consider to be distributed as a Logistic. ${ }^{5}$ The determinants of adoption are those outlined in Section 5.2 above and thus capture the influence of network effects, expectations, costs and size. In particular we expect size to play an important role in determining adoption. Table IV below reports the estimates of the selection equation.

\{Insert Table IV approximately here\} 
Results indicate that price expectations have a strong and negative impact on the probability to adopt, a result which is consistent with the literature reviewed in Section 2 predicting that expectations of future price decline are generally associated to adoption delays and/or non adoption. BANDWG has a positive and significant coefficient, suggesting that preference for compatibility with other firms increases the probability of adoption. As expected, SIZE is an important driver of adoption although the significance level of the coefficient is not very high Large firms have a higher probability of adopting Fast Ethernet. ${ }^{6}$ The coefficient of SWCOST, our proxy for the total cost of running the network, is negative, thus suggesting that high switching costs decrease the likelihood of adoption. Although consistent with the theory predicting that switching costs are an important source of inertia in adoption, the coefficient is not significant.

Having examined the factors affecting the probability to adopt, we then study the determinants of the timing of adoption. First, we estimate an Ordered Logistic and an Ordered Probit model. Second, we control for the robustness of our findings by carrying out Generalised Ordered Logistic and Multinomial Logistic estimations. We employ as covariates the same explanatory variables used in the estimation of the selection equation with the exclusion of SIZE and SWCOST and the inclusion of TECHCOMP. ${ }^{7}$ We control for sample selection bias by incorporating the estimates of the inverse Mills' ratio (MILLS). In particular, to assess the role of selection bias, for each model we estimate two specifications, with and without the inverse Mills' ratio. In the case of the Ordered Logistic, we estimate the following equation:

$$
P\left(Y_{i}>j\right)=F(X \beta)=\frac{\exp \left(\alpha_{j}+X_{i} \beta\right)}{1+\left[\exp \left(\alpha_{j}+X_{i} \beta\right)\right]}, \text { for } j=0,1,2
$$

$Y$ is the dependent variable (i.e. STATUS) which now does not include 23 Non adopter firms. This leaves us with 75 observations. $X$ is the vector of the determinants of the timing of adoption. The results of the Ordered Logistic and Ordered Probit estimations are reported in Table $\mathrm{V}$ below. 
\{Insert Table V approximately here\}

A comparison of the estimations with and without correcting for selection bias clearly highlights the correlation between adoption and timing of adoption. When MILLS is not included none of the explanatory variables is statistically significant. Indeed, both Model 2 and Model 4 perform badly. When MILLS is included, as in Model 3 and Model 5, the variable is statistically significant. This is an indication that correcting for sample selection bias is important both from the conceptual and from the statistical viewpoint. Unless we control for adoption, the estimated coefficients of the explanatory variables of the timing equation turn out to be biased. This suggests that the decision to upgrade from Ethernet to Fast Ethernet and timing of adoption are not disjointed.

The estimation results from the Ordered Logistic model after controlling for selection bias show that price expectations and virtual network effects significantly impact on timing of adoption. In particular, the positive coefficient for PRICEEXP suggests that firms that take into account future price declines in their decision to adopt Fast Ethernet tend to delay adoption. This result is consistent with the existing theoretical and empirical literature (reviewed in Section 2) on the impact of expectations on the speed of adoption. The negative coefficient for BANDWG, our measure of firms' preference for compatibility with other firms, indicates that a high preference for compatibility with other firms tends to speed up adoption. This result suggests that informational spillovers speed up adoption. It is worth remembering, however, that in principle spillovers may also delay adoption in those cases in which firms do not want to reveal the payoff from adoption and/or the characteristics of the technology for fear of being stranded by subsequent adopters. Our data do not seem to capture this effect. This is probably due to the fact that, at the time of the survey, Fast Ethernet was a mature standard with known characteristics and payoff from adoption. Results from the Ordered Probit estimation (Model 5) generally mirror those from the Ordered Logistic regression with the only exception of the coefficient for BANDWG that gains significance. 
Altogether, our results stress that both expectations and network effects are important determinants of the speed of upgrading. However, the evidence we found is quite mixed. Anticipating technological improvements does not seem to significantly influence timing of adoption as the coefficient on TECHEXP shows. Again, this follows from Fast Ethernet being a mature technology, which is less likely to experience further improvements in the near future. Moreover, VENDCOMP, our second proxy for virtual network effects, and TECHCOMP, our proxy for physical network effects are never significant. We explore the robustness of our results by running two additional models: a Generalised Ordered Logistic (GoLogit) and a Multinomial Logistic.

The choice of the GoLogit specification $(\mathrm{Fu}, 1998)$ stems from the desire to overcome a typical restriction of the Ordered Logistic estimates, which rely on the 'proportional odds assumption' and provide a unique estimate for each covariate as if coefficients were constrained to be the same across firm STATUS. ${ }^{8}$ Since we are interested in explaining heterogeneity in firm behaviour, we would like to be able to single out the determinants of differences of behaviour across categories of adopters. The GoLogit specification reveals the multi-equation nature of the ordered logistic approach and allows us to contrast the effects of the covariates on the probability of adoption for the different categories of respondents. The model we estimate is the following:

$$
P\left(Y_{i}>j\right)=G\left(X \beta_{j}\right)=\frac{\exp \left(\alpha_{j}+X_{i} \beta_{j}\right)}{1+\left[\alpha_{j}+\exp \left(X_{i} \beta_{j}\right)\right]}, \text { for } j=0, \ldots, M
$$

It can be noted that both the Ordered Logistic model and the Logistic regression model are special cases of the GoLogit model. When $M=1$ the GoLogit is equivalent to the Logistic regression model. Also the formula for the Ordered Logistic model (see equation 2) is similar to the GoLogit except that in the latter both Alphas and Betas have subscripts.

Results from the GoLogit estimation are reported in the first two columns of Table VI below. ${ }^{9}$ Positive coefficients indicate that higher values of the covariate make it more 
likely that the firm will be in a higher category of the variable STATUS than the current one. Negative coefficients indicate that higher values of the covariate increase the likelihood of being in the current or lower category.

\{Insert Table VI approximately here\}

The first column of Table VI contrasts Pioneers with Early adopters and Laggards. The second column contrasts Pioneers and Early adopters with Laggards. Concerning expectations, firms that take into account future price declines in their decision to adopt Fast Ethernet are more likely to be Early adopters or Laggards rather than Pioneers, as shown by the positive and significant coefficient of PRICEEXP in column one. Again, technological expectations do not seem to significantly influence timing of adoption. Concerning virtual network effects, BANDWG, our measure of firms' preference for compatibility with other firms, is negative and significant, therefore confirming that a high preference for compatibility with other firms speeds up adoption. Both results confirm our previous findings from the Ordered Logistic estimation. The coefficient of VENDCOMP, is negative and significant (see column one). This result suggests that preference for vendor compatibility speeds up adoption. Our interpretation is as follows. Purchasing from the same vendor enables firms to leverage on past learning, especially when product features are vendor specific. Relying on past learning in turn increases the speed of upgrading. As a consequence, a high preference for vendor compatibility decreases the likelihood of being Early adopters or Laggards. ${ }^{10}$ Finally, the coefficient of TECHCOMP, our proxy for physical network effects, is negative and significant only when Pioneers and Early adopters are contrasted with Laggards (see column two). Recall that this variable measures the importance of maintaining backward compatibility when migrating to a new standard. These results suggest that firms with a high preference for backward compatibility have a lower probability of being Laggards. Overall, it can be argued that preference for (vertical) backward compatibility generally tends to speed up adoption. This result is somewhat expected given the compatibility between Ethernet and Fast Ethernet. 
We can compare our GoLogit estimations with the estimates from a Multinomial Logistic model. Given that our dependent variable STATUS is inherently ordered, a Multinomial Logistic estimation is less appropriate than the GoLogit. However, it provides separate coefficients for each covariate allowing us to further check our results. In this case, positive coefficients indicate that higher values of the covariate make it more likely that the firm will be in the current category of the variable STATUS. Negative coefficients indicate that higher values of the covariate decrease the likelihood of being in the current category of the variable STATUS. The third column of Table VI summarises the results from the comparison between Pioneers and the Laggards. Results are similar to previous results from the GoLogit. Spillovers linked to vendor compatibility and bandwagon effect speed up adoption by increasing the probability of being Pioneers. Price expectations instead delay adoption. When we compare Early adopters and Laggards (see column four), it is interesting to note that only physical network effects matter. In particular, firms with a high preference for backward compatibility have a higher probability of being Early adopters.

All in all, the results from our exploratory sensitivity analysis seem to confirm the estimates from our previous models concerning the importance of price expectations and 'spillovers induced' virtual network effects. However, by providing separate coefficients for each category of adopters, these models enable us to gain additional insights on the determinants of the timing of adoption. In particular, vendor compatibility and physical network effects seem to become significant only for certain categories of firms (Pioneers and Early adopters).

\section{Conclusions}

This paper took a firm level approach to study the factors affecting the timing of adoption of Fast Ethernet, a high speed LAN standard. Relying on a detailed survey of 128 SMEs active in the computer service industry in Italy, we were able to collect information on both the technologies in use and the determinants of adoption decisions by LAN managers. The information was used to study the impact of expectations and 
network effects on timing of adoption of different types of firms categorised by speed of adoption. Controlling for sample selection bias, the following results were found.

First, we provided evidence to support the hypothesis that expectations generally tend to delay adoption. This confirms the conclusions of the existing theoretical literature on the subject, as well as of the previous empirical study carried out by Weiss (1996), although in our case it is price rather than technological expectations that seem to play the most important role. Second, we presented two pieces of evidence on the impact of network effects on timing of adoption. First, we found that indirect network effects impact significantly on timing of Fast Ethernet adoption. Second, the level of detail of our survey enabled us to distinguish different types of indirect network effect. We found that virtual network effects generally speed up adoption. In particular, our findings suggest that the presence of informational spillovers from other adopters speeds up adoption of any category of firms, and that spillovers from vendors positively impact only on Early adopters. Preference for backward (vertical) compatibility also speeds up adoption, therefore supporting the view that in technical systems physical indirect network effects matter for adoption. Finally, in the sample selection equation, we also found that large firms are more likely to adopt.

Although promising and encouraging, especially given the scanty existing empirical evidence on the role of expectations, these preliminary findings are subject to some limitations. First, we have 98 firms in our sample, not a large number. Even if this number is comparable to previous studies in the field that adopted a similar methodology (Weiss, 1996), it constrains the number of independent variables that can be used in the estimations. An attempt to extend the sample by surveying more firms is currently being carried out. Working on a larger sample of firms would allow us to control for firm specific effects, other than size, that may influence the speed of upgrading such as firm competencies. Second, the survey targeted firms from the computer service industry (NACE 72) only. These are generally high tech firms with a high propensity to adopt new technologies. As a consequence, our results may have over-sampled the number of Fast Ethernet adopters. Moreover, if patterns of adoption 
are sectoral specific, as previous studies highlighted (Windrum and de Berranger, 2003), we should expect firms from low tech sectors to behave differently. Extending the survey to low-medium tech industries would help to explore further this issue. Finally, this paper considered the case of two mature standards. Ethernet has been the dominant standard for LANs since the end of the 1980s, Fast Ethernet has been commercialised since mid 1990s. It may be argued that focussing on the decision to adopt a mature standard may lead to an underestimation of the role of technological expectations as determinants of the speed of upgrading as indeed we found. While this choice does not affect the relevance of the results with respect to the differences we found across the different categories of adopters, focusing on less mature standards may bring different results, particularly concerning the role of technological vis-à-vis price expectations as determinants of the speed of upgrade. We will explore all these issues further in future work. 
1 Several surveys of equilibrium diffusion models exist in the literature (Stoneman, 1983; Dosi, 1991). For this short review, we follow Stoneman (2002).

2 Empirical research on network effects has been growing over the last decade. The table highlights only a selection of empirical contributions and the indicators that have been used as proxies for the network effect. It does not aim at being exhaustive.

${ }^{3}$ Additional information reveals that client server applications (81\%), intranet and extranet developments (30\% and 32\% respectively) followed by emails (22\%) were the most important drivers of firms' decision to adopt new LAN standards and equipment.

4 This classification is clearly inspired by Rogers (2003), who identifies five 'ideal types' of adopters (Innovators, Early adopters, Early majority, Late majority and Laggards). However, while Roger's distinction is done on the basis of sociological as well as behavioural attitudes toward innovation, our distinction is not driven by the same concerns.

${ }^{5}$ Another possibility is that the residual is distributed as a Probit. Both the Logit and the Probit distribution are symmetric, bell shaped, and widely used in the literature on innovation diffusion (see Davies, 1979). In this case we have found that the Logit specification is preferred and we report on this.

6 This result holds when using alternative proxies for size such as the number of employees, the number of connected network nodes, and the number of connected company sites. Bigger firms have larger networks in place and are more likely to experience congestion problems. Upgrading to Fast Ethernet is a way of reducing congestion.

7 SIZE and SWCOST are excluded to ensure some variability between the two steps of the model, in order to reduce simultaneity problems leading to possible spurious significance of sample selection effects (Stoneman and Battisti, 2003: 35) and because they are traditionally considered to influence the probability to adopt adoption rather than the timing of adoption. TECHCOMP was excluded from the selection equation because of collinearity with SIZE.

8 See Williams (2005) for a discussion of the shortcomings of the proportional odds assumption.

${ }_{9}^{9}$ Our implementation somewhat deviates from the two-step traditional model of Heckman in the sense that our model of the effects of sample selection does not follow the traditional (simple linear) approach. For this reason, we have not adjusted the standard errors for the estimated GoLogit and Multinominal Logistic coefficients. This type of adjustment is likely to be quite complex and goes beyond the scope of our sensitivity analysis, which aims instead at providing a preliminary exploration of the effect of selection on timing of adoption.

10 Recall that, as argued above, preference for vendor compatibility may, in principle, also delay adoption to the extent to what repeated purchases from the same vendor may also increase the fear of becoming locked in to a specific manufacturer. Our findings do not seem to support this hypothesis. 


\section{REFERENCES}

Augerau, A. (1999), The Battle for 56K: Did Network Effects Matter?. Working Paper, Kellog Graduate School of Management

Balcer, Y. and S. A. Lippman (1984), Technological Expectations and Adoption of Improved Technology: Journal of Economic Theory, 34, 292-318

Battisti, G. and P. Stoneman (2003), The Intra-firm Diffusion of New Process Technologies: RP0304, Aston Business School Research Institute.

Cheng, J. Z., Hsiao-Cheng, Y. and W. D. Sincoskie (2005), Meeting the Broadband Access Infrastructure Demands: the Promise of Gigabit Ethernet: Technological Forecasting $\mathcal{E}$ Social Change, 72: 1-10

Choi, J. P. (1997), Herd Behavior, the "Penguin Effect", and the Suppression of Informational Diffusion: an Analysis of Informational Externalities and Payoff Interdependency: RAND Journal of Economics, 28, (3): 407-425

Christensen, K.J., Haas L.C., Noel F.E. and N. C. Strole (1995), Local area networks. Evolving from shared to switched access: IBM Systems Journal, 34: 347-374

Church, J. and N. Gandal (2004), Platform Competitions in Telecommunications: CEPR Discussion Paper No 4659 forthcoming in The Handbook of Telecommunications, Volume 2, M. Cave, S. Majumdar and I. Vogelsgang (eds.)

Cohen, W. and D. Levinthal (1989), Innovation and Learning: the Two Faces of R\&D: The Economic Journal, 99, 569-596

David, P.A. (1969), A Contribution to the Theory of Diffusion: memorandum No 71, Stanford Centre for Research in Economic Growth

David, P. A. and T. Olsen (1986), Equilibrium Dynamics of Diffusion when Incremental Technological Innovations are foreseen: Ricerche Economiche, XL, (4): 738-770

Davies, S. (1979), The Diffusion Of Process Innovations. Cambridge, UK, Cambridge University Press

Dosi, G. (1991), The Research on Innovation Diffusion: an Assessment, in: N. Nakicenovic and A. Grubler: Diffusion of Technologies and Social Behaviour. Berlin, Springer-Verlag

Dranove, D. and N. Gandal (2003), The DVD vs. DIVX Standard War: Empirical Evidence on Network Effects and Preannouncement Effects: Journal of Economics and Management Strategy, 12: 363-386 
Economides, N. and C. Himmelberg (1995), Critical Mass and Network Size with Application to the US Fax Market: Discussion Paper no. EC-95-11, Stern School of Business, N.Y.U

Forman, C. and P. Chen (2004), Switching Costs and Network Effects in the Market for Routers and Switches, mimeo, Graduate School of Industrial Administration, Carnegie Mellon University

Fu, V. (1998), Estimating Generalised Ordered Logit Models: Stata Technical Bulletin, 8: 160-164.

Gandal, N. (1994), Hedonic Price Indexes for Spreadsheets and an Empirical Test for Network Externalities: RAND Journal of Economics, 25, (1): 160-70

Gandal, N., M. Kende and R. Rob (2000), The Dynamics of Technological Adoption in Hardware/Software Systems: The Case of Compact Disc Players: RAND Journal of Economics, 31, (1): 43-61

Goolsbee, A. and P. Klenow (1999), Evidence on Learning and Network Externalities in the Diffusion of Home Computers: University of Chicago, mimeo

Gowrisankaran, G. and J. Stavins (2002), Network Externalities and Technology Adoption: Lessons from Electronic Payments: RAND Journal of Economics, forthcoming

Hannan, T. and J. McDowell (1984), The Determinants of Technology Adoption: the Case of the Banking Firm: RAND Journal of Economics, 15, (3): 328-335

Heckman, J. (1979), Sample Selection Bias as a Specification Error: Econometrica, 47: 153161.

Koski, H. (1999), The Installed Base Effect: Some Empirical Evidence from the Microcomputer Market: Economics of Innovation and New Technology, 8, 273-310

Rogers, E. M. (2003), Diffusion of Innovations. New York, Free Press

Rosenberg, N. (1976a), On Technological Expectations: The Economic Journal, 86, (343): 523-535.

Saloner, G. and S. Shepard (1995), Adoption of Technologies with Network Effects: an Empirical Examination of the Adoption of Automated Teller Machines: RAND Journal of Economics, 26: 479-501

Stoneman, P. (1983), The Economic Analysis of Technological Change. Oxford, Oxford University Press

Stoneman, P. (2002), The Economics of Technological Diffusion. Oxford, Blackwell 
Stoneman, P. and N. J. Ireland (1983), The Role of Supply Factors in the Diffusion of New Process Technology: The Economic Journal, 93, (396): 66-78

von Burg, U. (2001), The triumph of Ethernet. Stanford, Stanford University Press

Weiss, A. M. (1994), The Effects of Expectations on Technological Adoption: Some Empirical Evidence: The Journal of Industrial Economics, XLII (4): 341-60

Williams, R. (2005), Gologit 2: Generalised Logistic Regression/Partial Proportional Odds Models for Ordinal Dependent Variables: Last revised July 29, 2005. (http:/ / www.nd.edu/ rwilliam/gologit2/gologit2.pdf), last accessed December 30th, 2005.

Windrum, P. and P. de Berranger (2003), Factors Affecting the Adoption of Intranets and Extranets by SMEs: a UK Study: WP 03/10, Manchester Metropolitan University Business School, September 2003. 
FIGURE I

DiFFUSION OF FAST ETHERNET STANDARD (PORT SHIPMENTS IN 000S)

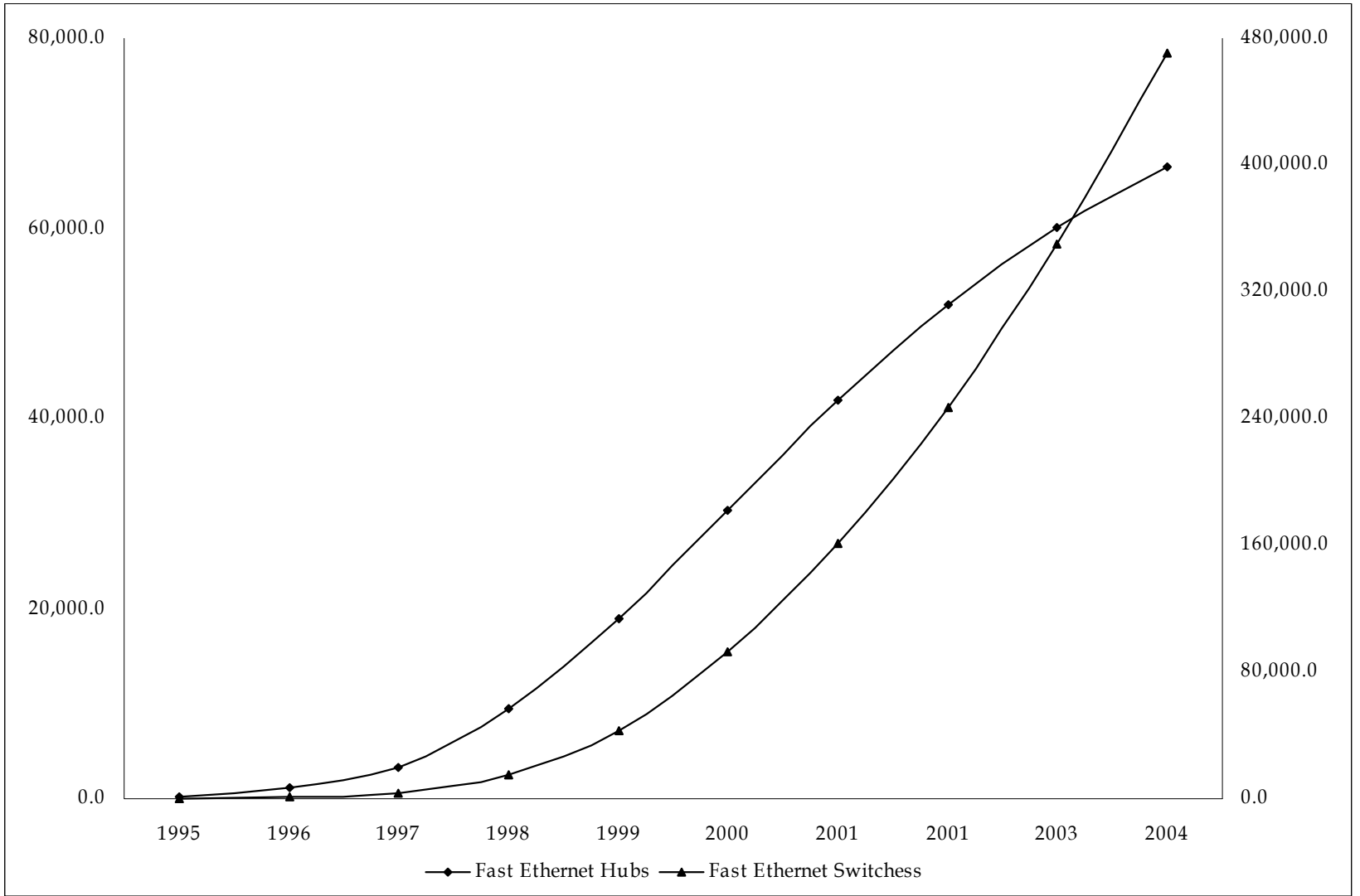

Source: Dell'Oro Group Market Research 
TABLE I

SUMMARY OF SELECTED EMPIRICAL STUDIES OF NETWORK EFFECTS

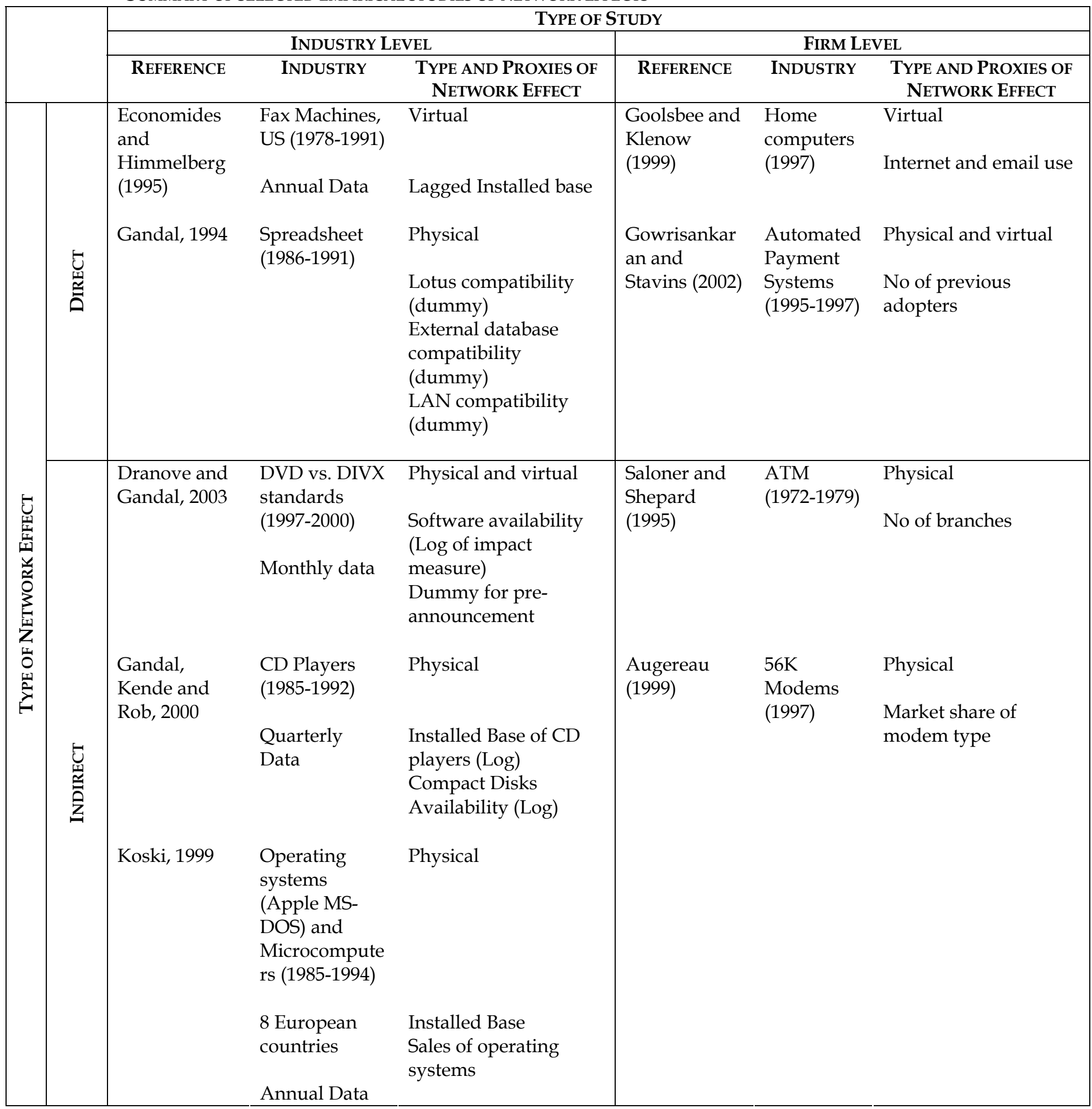


TABLE II

PATTERN OF LAN STANDARD ADOPTION (NO OF FIRMS)

\begin{tabular}{lccccc}
\hline & $<12$ & $12-18$ & $18-24$ & $>24$ & $\%$ OF ADOPTERS \\
\hline ETHERNET & 4 & 21 & 35 & 25 & 87 \\
FAST ETHERNET & 7 & 12 & 32 & 24 & 76 \\
TOKEN RING & 3 & 7 & 12 & 2 & 24 \\
FDDI & 1 & 2 & 7 & 2 & 12 \\
ATM & 0 & 0 & 2 & 0 & 2 \\
\hline
\end{tabular}


TABLE III

PATTERN OF ETHERNET AND FAST ETHERNET ADOPTION BY FIRM CHARACTERISTICS

\begin{tabular}{l|c|cccc|cccc}
\hline & SAMPLE & \multicolumn{5}{|c|}{ ETHERNET } & \multicolumn{3}{c}{ FAST ETHERNET } \\
\cline { 2 - 9 } & & $<12$ & $12-18$ & $18-24$ & $>24$ & $<12$ & $12-18$ & $18-24$ & $>24$ \\
\hline FIRM TYPE & & & & & & & & & \\
National & $41 \%$ & $2 \%$ & $7 \%$ & $14 \%$ & $15 \%$ & $3 \%$ & $2 \%$ & $10 \%$ & $12 \%$ \\
International & $56 \%$ & $2 \%$ & $14 \%$ & $20 \%$ & $10 \%$ & $3 \%$ & $10 \%$ & $20 \%$ & $12 \%$ \\
Local & $1 \%$ & - & - & - & - & - & - & $1 \%$ & - \\
Regional & $2 \%$ & - & - & $1 \%$ & - & $1 \%$ & - & $1 \%$ & - \\
\hline NO OF EMPLOYEES & & & & & & & & & \\
$<500$ & $73 \%$ & $3 \%$ & $15 \%$ & $24 \%$ & $21 \%$ & $6 \%$ & $7 \%$ & $24 \%$ & $17 \%$ \\
$500-999$ & $20 \%$ & $1 \%$ & $6 \%$ & $7 \%$ & $1 \%$ & $1 \%$ & $5 \%$ & $5 \%$ & $3 \%$ \\
$1000-5000$ & $7 \%$ & - & - & $4 \%$ & $3 \%$ & - & - & $3 \%$ & $4 \%$ \\
\hline REVENUES(EUROS) & & & & & & & & & \\
$100 K-499 K$ & $9 \%$ & - & $1 \%$ & $3 \%$ & $2 \%$ & $1 \%$ & - & $4 \%$ & $3 \%$ \\
$500 K-999 K$ & $33 \%$ & $2 \%$ & $6 \%$ & $13 \%$ & $9 \%$ & $2 \%$ & $3 \%$ & $5 \%$ & $7 \%$ \\
1 M-10M & $41 \%$ & $2 \%$ & $11 \%$ & $10 \%$ & $10 \%$ & $2 \%$ & $5 \%$ & $18 \%$ & $10 \%$ \\
$>10 M$ & $17 \%$ & - & $3 \%$ & $9 \%$ & $4 \%$ & $2 \%$ & $4 \%$ & $5 \%$ & $4 \%$ \\
\hline TYPE OF NETWORK & & & & & & & & & \\
Internetwork & $26 \%$ & $1 \%$ & $3 \%$ & $12 \%$ & $7 \%$ & - & $2 \%$ & $8 \%$ & $6 \%$ \\
LAN & $58 \%$ & $3 \%$ & $17 \%$ & $15 \%$ & $12 \%$ & $6 \%$ & $9 \%$ & $18 \%$ & $14 \%$ \\
WAN & $16 \%$ & - & $1 \%$ & $8 \%$ & $6 \%$ & $1 \%$ & $1 \%$ & $6 \%$ & $4 \%$ \\
\hline NO OF NODES & & & & & & & & & \\
\hline$<50$ & $50 \%$ & $3 \%$ & $9 \%$ & $18 \%$ & $18 \%$ & $4 \%$ & $5 \%$ & $18 \%$ & $14 \%$ \\
$50-100$ & $27 \%$ & $1 \%$ & $9 \%$ & $11 \%$ & $3 \%$ & $2 \%$ & $3 \%$ & $9 \%$ & $5 \%$ \\
$101-250$ & $10 \%$ & - & $3 \%$ & $3 \%$ & $3 \%$ & $1 \%$ & $3 \%$ & $1 \%$ & $3 \%$ \\
$251-500$ & $5 \%$ & - & - & $3 \%$ & - & - & $1 \%$ & $2 \%$ & $1 \%$ \\
$>500$ & $3 \%$ & - & - & - & $1 \%$ & - & - & $2 \%$ & $1 \%$ \\
\hline
\end{tabular}


TABLE IV

EXPLORING SAMPLE SELECTION BIAS. LOGIT SELECTION EQUATION. DEPENDENT VARIABLE: FAST ETHERNET ADOPTION

\begin{tabular}{|c|c|}
\hline INDEPENDENT VARIABLE & 1 \\
\hline BANDWG & 0.722 \\
\hline & {$[0.399]^{*}$} \\
\hline VENDCOMP & 0.081 \\
\hline & [0.346] \\
\hline PRICEEXP & -0.976 \\
\hline & {$[0.361]^{* * *}$} \\
\hline TECHEXP & 0.203 \\
\hline & [0.384] \\
\hline SIZE & 0.659 \\
\hline & {$[0.321]^{* *}$} \\
\hline SWCOST & -1.694 \\
\hline & [1.947] \\
\hline CONSTANT & -1.142 \\
\hline & [3.038] \\
\hline Observations & 98 \\
\hline Log Pseudo LL & -44.78 \\
\hline Wald Chisq & $12.12^{* *}$ \\
\hline Pseudo Rsq & 0.161 \\
\hline
\end{tabular}

* denotes $10 \%$ significance level, ** denotes $5 \%$ significance level.

*** denotes $1 \%$ significance level, Robust standard errors in brackets 


\begin{tabular}{|c|c|c|c|c|}
\hline \multirow{2}{*}{ INDEPENDENT VARIABLE } & \multicolumn{2}{|c|}{ ORDERED LOGIT } & \multicolumn{2}{|c|}{ ORDERED PROBIT } \\
\hline & 2 & 3 & 4 & 5 \\
\hline $\begin{array}{l}\text { TECHCOMP } \\
\text { (PHYSICAL NE) }\end{array}$ & $\begin{array}{c}-0.161 \\
{[0.286]}\end{array}$ & $\begin{array}{c}-0.172 \\
{[0.282]}\end{array}$ & $\begin{array}{l}-0.124 \\
{[0.170]}\end{array}$ & $\begin{array}{c}-0.130 \\
{[0.169]}\end{array}$ \\
\hline $\begin{array}{l}\text { BANDWG } \\
\text { (VIRTUAL NE) }\end{array}$ & $\begin{array}{l}-0.435 \\
{[0.472]}\end{array}$ & $\begin{array}{c}-0.945 \\
{[0.487]^{*}} \\
\end{array}$ & $\begin{array}{l}-0.281 \\
{[0.274]}\end{array}$ & $\begin{array}{c}-0.597 \\
{[0.293]^{* *}}\end{array}$ \\
\hline $\begin{array}{l}\text { VENDCOMP } \\
\text { (VIRTUAL NE) }\end{array}$ & $\begin{array}{l}-0.376 \\
{[0.377]}\end{array}$ & $\begin{array}{l}-0.536 \\
{[0.393]}\end{array}$ & $\begin{array}{l}-0.240 \\
{[0.210]}\end{array}$ & $\begin{array}{c}-0.331 \\
{[0.213]}\end{array}$ \\
\hline PRICEEXP & $\begin{array}{c}0.129 \\
{[0.296]}\end{array}$ & $\begin{array}{c}0.568 \\
{[0.345]^{*}}\end{array}$ & $\begin{array}{c}0.087 \\
{[0.167]}\end{array}$ & $\begin{array}{c}0.361 \\
{[0.201]^{*}}\end{array}$ \\
\hline TECHEXP & $\begin{array}{l}-0.098 \\
{[0.413]}\end{array}$ & $\begin{array}{l}-0.266 \\
{[0.413]} \\
\end{array}$ & $\begin{array}{l}-0.055 \\
{[0.223]}\end{array}$ & $\begin{array}{l}-0.170 \\
{[0.223]}\end{array}$ \\
\hline MILLS & & $\begin{array}{c}-2.787 \\
{[1.144]^{* *}}\end{array}$ & & $\begin{array}{c}-1.696 \\
{[0.704]^{* *}}\end{array}$ \\
\hline Observations & 75 & 75 & 75 & 75 \\
\hline Log Pseudo LL & -77.31 & -74.90 & -77.20 & -74.80 \\
\hline Wald Chisq & 3.11 & $9.52^{*}$ & 3.39 & $9.61^{*}$ \\
\hline Pseudo Rsq & 0.017 & 0.047 & 0.018 & 0.050 \\
\hline
\end{tabular}

* denotes $10 \%$ significance level, ${ }^{* *}$ denotes $5 \%$ significance level, ${ }^{* * *}$ denotes $1 \%$ significance level.

Robust standard errors in brackets 


\section{TABLE VI}

DETERMINANTS OF TIMING OF ADOPTION. EXPLORING THE ROBUSTNESS OF RESULTS. GENERALISED ORDERED LOGIT AND MULTINOMIAL LOGIT MODEL ESTIMATION. DEPENDENT VARIABLE: STATUS

\begin{tabular}{|c|c|c|c|c|c|}
\hline \multirow{2}{*}{$\begin{array}{l}\text { INDEPENDENT } \\
\text { VARIABLE }\end{array}$} & \multicolumn{2}{|c|}{ GENERALISED ORDERED LOGIT } & \multicolumn{3}{|c|}{ MULTINOMIAL LOGIT } \\
\hline & [0 vs. 1-2] & [0-1 vs. 2] & [0 vs. 2] & [1 vs. 2] & [1 vs. 0$]$ \\
\hline TECHCOMP & -0.184 & -1.122 & 0.623 & 1.134 & 0.511 \\
\hline (PHYsiCAL NE) & [0.357] & {$[0.485]^{* *}$} & {$[0.550]$} & {$[0.518]^{* *}$} & {$[0.414]$} \\
\hline BANDWG & -1.234 & -0.949 & 1.649 & 0.634 & -1.015 \\
\hline (VIRTUAL NE) & {$[0.641]^{*}$} & [0.799] & {$[0.842]^{* *}$} & {$[0.800]$} & [0.743] \\
\hline VENDCOMP & -0.863 & -0.77 & 0.907 & 0.547 & -0.359 \\
\hline (VIRTUAL NE) & {$[0.520]^{*}$} & [0.556] & {$[0.546]^{*}$} & [0.512] & [0.465] \\
\hline \multirow[t]{2}{*}{ PRICEEXP } & 0.761 & 0.769 & -0.895 & -0.448 & 0.447 \\
\hline & {$[0.392]^{*}$} & {$[0.530]$} & {$[0.543]^{*}$} & [0.547] & {$[0.444]$} \\
\hline \multirow[t]{2}{*}{ TECHEXP } & -0.345 & -0.166 & 0.394 & -0.210 & -0.604 \\
\hline & {$[0.414]$} & [0.506] & [0.553] & [0.552] & [0.433] \\
\hline \multirow[t]{2}{*}{ MILLS } & -4.843 & -1.959 & 3.485 & -0.214 & -3.699 \\
\hline & {$[1.672]^{* * *}$} & [2.491] & {$[1.754]^{* *}$} & [1.869] & {$[1.650]^{* *}$} \\
\hline \multirow[t]{2}{*}{ CONSTANT } & 7.781 & 4.964 & -8.503 & -3.229 & 5.274 \\
\hline & {$[3.162]^{* *}$} & [3.843] & {$[4.053]^{* *}$} & [4.030] & [3.591] \\
\hline Observations & \multicolumn{2}{|c|}{75} & \multicolumn{3}{|c|}{75} \\
\hline Log Pseudo LL & \multicolumn{2}{|c|}{-71.48} & \multicolumn{3}{|c|}{-71.31} \\
\hline Wald Chisq & \multicolumn{2}{|c|}{$14.21^{*}$} & \multicolumn{3}{|c|}{$15.50^{*}$} \\
\hline Pseudo Rsq & \multicolumn{2}{|c|}{0.090} & \multicolumn{3}{|c|}{0.092} \\
\hline
\end{tabular}

* denotes 10\% significance level, ${ }^{* *}$ denotes $5 \%$ significance level, *** denotes $1 \%$ significance level.

Robust standard errors in brackets. J=0 Pioneer, J=1Early Adopter, J=2 Laggard. 


\section{APPENDIX}

TABLE A1

DESCRIPTIVE STATISTICS

\begin{tabular}{cccccc}
\hline Variable & Mean & S. D. & Min & Max & Observations \\
\hline STATUS & 0.739 & 1.097 & 0 & 3 & 98 \\
BWDCOMP & 1.890 & 0.780 & 1 & 4 & 98 \\
BANDWG & 3.561 & 0.643 & 1 & 4 & 98 \\
VENDCOMP & 2.612 & 0.713 & 1 & 4 & 98 \\
PRICEEXP & 2.653 & 0.790 & 1 & 4 & 98 \\
TECHEXP & 2.775 & 0.711 & 1 & 4 & 98 \\
SIZE & 4.663 & 0.873 & 3 & 6 & 98 \\
SWCOST & 0.739 & 0.142 & 0.400 & 1 & 98 \\
MILLS & 0.299 & 0.443 & 0.001 & 2.651 & 98 \\
\hline
\end{tabular}

